\title{
Management of Hypertension (HTN) in a Cardiology Department in Bamako (Mali): Financial Aspects
}

\author{
Hamidou Oumar Bâa ${ }^{*}$, Ichaka Menta1, Ibrahima Sangaré1, Noumou Sidibé1, Youssouf Camara ${ }^{2}$, \\ Souleymane Coulibaly ${ }^{3}$, Hamidou Camara ${ }^{1}$, Cheick Hamala Fofana ${ }^{1}$, Aladji Traoré1, \\ Adama Sogodogo1, Mamadou Touré1, Kéita Asmaou Maiga3, Doumbia Coumba Thiam², \\ Adama Daou ${ }^{4}$, Kassoum Mamourou Sanogo ${ }^{1}$
}

\footnotetext{
${ }^{1}$ University Hospital Gabriel Touré, Bamako, Mali

${ }^{2}$ University Hospital Sidy Bocar Sall, Kati, Mali

${ }^{3}$ University Hospital Mother Children, Bamako, Mali

${ }^{4}$ National Center for Disease Fighting, Bamako, Mali

Email: *bhamiba@yahoo.fr
}

\begin{abstract}
How to cite this paper: Bâ, H.O., Menta, I., Sangaré, I., Sidibé, N., Camara, Y., Coulibaly, S., Camara, H., Fofana, C.H., Traoré, A., Sogodogo, A., Touré, M., Maiga, K.A., Thiam, D.C., Daou, A. and Sanogo, K.M. (2019) Management of Hypertension (HTN) in a Cardiology Department in Bamako (Mali): Financial Aspects. World Journal of Cardiovascular Diseases, 9, 394-403. https://doi.org/10.4236/wjcd.2019.96035
\end{abstract}

Received: May 11, 2019

Accepted: June 23, 2019

Published: June 26, 2019

Copyright (๑) 2019 by author(s) and Scientific Research Publishing Inc. This work is licensed under the Creative Commons Attribution International License (CC BY 4.0).

http://creativecommons.org/licenses/by/4.0/

\section{(c) (i) Open Access}

\begin{abstract}
Background: Studies on financial aspects of High blood pressure management are rare and old without differentiating categories of expenses. On the other hand there is an evolution in health system with the introduction of a medical insurance. Objective: We performed this study to estimate costs related to insurance status. Methodology: The prospective study on patients aged 15 years and older extended from 01 May to 31 August 2016 and was carried out in the cardiology department of the University Hospital Gabriel Touré. Only newly detected or untreated hypertensive patients were included. Sociodemographic data, those on physical examination and financial management (transport, consultation, labor tests and purchase of drugs) were collected. Regarding costs, patients were directly asked about: how much did you spend for transport, consultation, labor tests and drugs? Data analysis was carried out by comparing patients with health insurance (Ins+) and those without it (Ins-). The recorded data were inserted in a MS Access database, preliminarily processed by MS Excel and imported to SPSS version 20 for analysis. Results: Mean total cost of care was 57,018 FCFA [50,139 - 63,897] (around 92 USD). It was 50,072 [42,182 - 57,963] for the Ins- group against $79,670[66,777-92,563]$ for the Ins+ group with a $p$ value $<0.0001$. Highest amounts for spending were for cardiovascular medication and labor tests with means of 19,255 FCFA ( 32 USD) and 18,813 FCFA (30 USD). Mean consultation fee was significantly higher for Ins+ patients: 4064 FCFA with IC (95\%) [3210 - 4917] versus 3124 with IC (95\%) [2774 - 3474] for Ins- pa-
\end{abstract}


tients and $\mathrm{p}=0.018$. For ECG, however, mean costs were higher for Ins- patients with 6460 [5944 - 6976] against 5115 [4871 - 5360] for Ins+ patients, $p$ $=0.001$. Conclusion: Health insurance has few subscribers compared to patients requiring medical care. It increases the global costs of care while facilitating access to care for those who benefit from it.

\section{Keywords}

Hypertension, New Patients, Untreated Patients, Costs, Cardiology, Bamako

\section{Introduction}

High blood pressure or hypertension (HTN) is one of the most important cardiovascular risk factors (CVrf) in the world [1] [2] [3], also in Africa, with prevalence even higher than in the rest of the world. Many prevalence studies on HTN [4] [5] [6] attest this heavy burden for all countries, especially those in African continent.

Although the epidemiological aspects of HTN have been the subject of many studies, the financial aspects of its management have been less studied. There are some studies conducted in Africa on hospitalized patients [7] [8] or on the general population [9].

In Mali published studies on the financial aspect are rare and more than 20 years old [10]. These studies do not differentiate between the categories of expenses related to the treatment of hypertension. In addition, indirect costs, particularly related to the transport to the health care facility, have not been evaluated.

Mali has seen a major change in its health care system with the establishment of a medical insurance system in 2009. There are 2 components, the first a compulsory health insurance regime (AMO in French) for public and private sectors employees and also self-employed workers who may voluntarily subscribe and a medical assistance plan (RAMED in French) for patients recognized as "indigent". In AMO regime patients pay $30 \%$ for consultation and labor assessments and $20 \%$ for hospitalization, whereas patients in the RAMED regime have nothing to pay.

Our study proposes to report on costs, giving actualized data and especially comparing the different costs for patients with and without medical insurance.

\section{Methodology}

This sample comes from a prospective study on patients aged 15 years and over from January 1rst to August 312016 in the cardiology department of the University Hospital Gabriel Touré (UH GT).

Patient selection

During the study period 922 patients were recruited successively among whom 465 new ones including 365 hypertensive and 280 new hypertensive or untreated hypertensive as indicated on the diagram (Figure 1). 


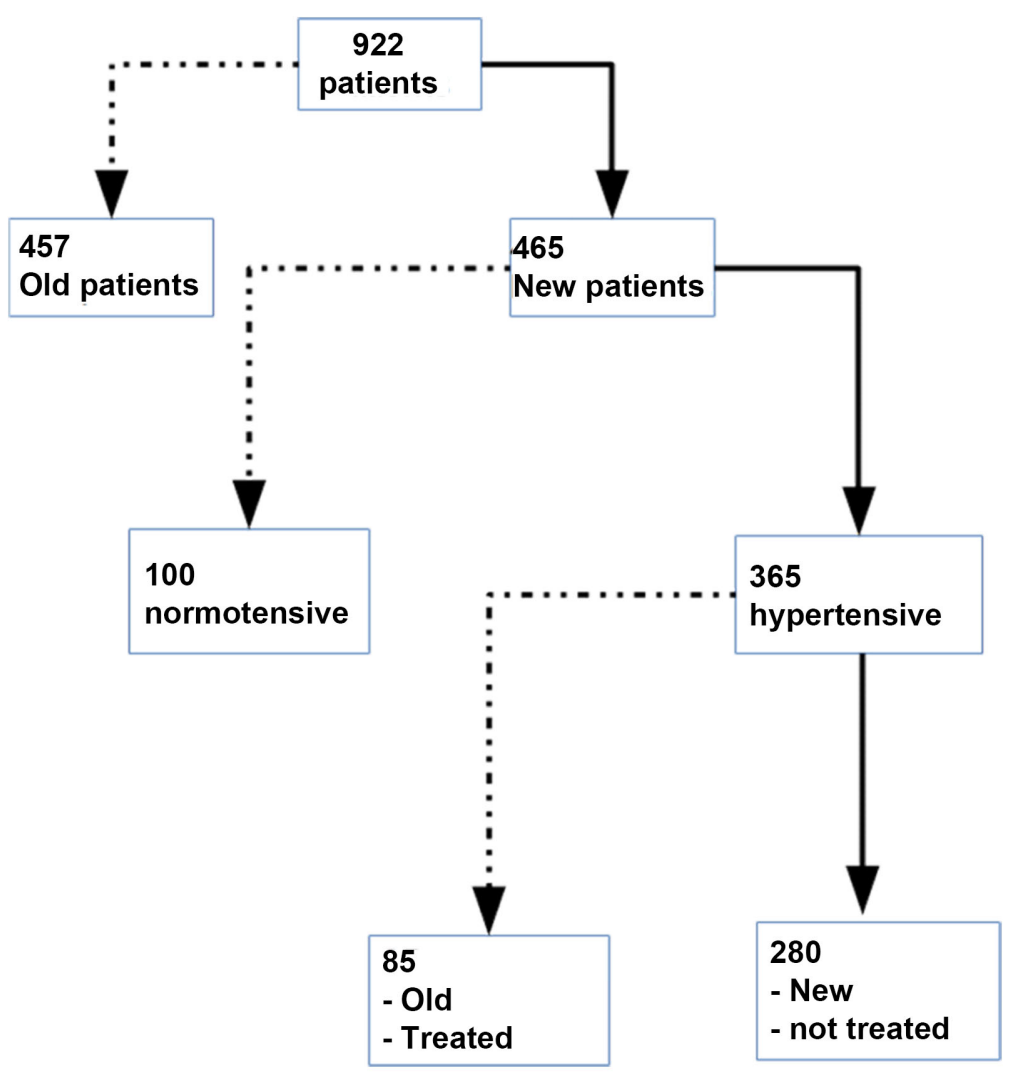

Figure 1. Patient selection for the cost study among hypertensive patients in the cardiology department of the University Hospital Cardiology.

These 280 patients were divided into 2 groups according to the health insurance status: those with an insurance are called Ins+ and those without as Ins-.

Data Collection:

For each patient, data collection covers sociodemographic characteristics, anthropometric measurements (body mass index (BMI), waist circumference (WC), ratio of waist circumference/hip circumference (WHr)).

In addition, the various costs related to expenses (moving to health facility, consultation fee, costs for labor assessments and for the purchase of medicines) were collected.

Costs for patients with medical insurance, except for transport, have been adjusted, to obtain the real costs, as they pay only a third for consultation and labor assessement and a fifth in case of hospitalization. All costs are expressed in currency of West Africa ( 1 USD $=619.88$ FCFA XOF) at study time.

Data were first recordedon a formulary and then inserted in a Microsoft Access database, built for this purpose.

Data Analysis:

It was performed by comparing patients with and without medical insurance respectively Ins+ and Ins- regarding anthropometric, socio-demographic data, other associated CVrf and finally the different costs for health care.

Quantitative variables are expressed as mean with $95 \%$ confidence interval, 
standard deviation (SD) and an analysis of variance was performed to test differences.

Qualitative variables are presented as proportions and cross-tables with the appropriate tests (Chi-square test). The results considered significant for $\mathrm{p}<$ 0.05 .

The data inserted in the Microsoft Access database were previously processed by Microsoft Excel and analyzed by SPSS version 20 .

\section{Results}

For the study, 280 hypertensive patients (newly diagnosed or never treated) were identified making $30.37 \%$ of the initial sample. A proportion of $23.2 \%$ (65 patients) had a medical insurance.

The means for age, WHr, systolic, diastolic and mean arterial pressures did not differ significantly. BMI, WC, and pulsed pressure (PP) were higher for Ins+ with resp. $28.57 \mathrm{Kg} / \mathrm{m}^{2}, 94.54 \mathrm{~cm}$ and $66.18 \mathrm{mmHg}$ versus 25, 88 and 60.27 (resp. $\mathrm{p}=0.003,0.002$ and 0.026$)$. Heart rate was lower in the Ins- group $(84.47 / \mathrm{min}$ against $90.47 / \mathrm{min}$ (Table 1 ).

There was a significant increase in the proportion of patients with medical insurance with age up to age 74 , as well as with the increase in the level of education (Table 2). Other CVrf were not statistically different (Table 3).

The mean total cost of care was 57,018 FCFA [50,139 - 63,897] for the study period. It was 50,072 [42,182 - 57,963] for the Ins- group and 79,670 [66,777 $92,563]$ for the Ins+ group with a statistically significant difference $(p<0.0001)$ (Table 4).

The mean consultation fee was significantly higher for the Ins+ group: 4064 FCFA [3210 - 4917] against 3124 [2774 - 3474] for the Ins- group with $p=0.018$.

Table 1. Anthropometric data for 280 newly diagnosed or not treated hypertensive patients in the cardiology department of the University Hospital Gabriel Touré.

\begin{tabular}{|c|c|c|c|c|c|c|c|}
\hline \multirow{2}{*}{ Variables $(\mathrm{N})$} & \multicolumn{2}{|c|}{ Ins- } & \multicolumn{2}{|c|}{ Ins+ } & \multicolumn{2}{|c|}{ Total } & \multirow{2}{*}{$\mathrm{p}$} \\
\hline & Mean \pm SD & $\mathrm{CI}_{95 \%}$ & Mean \pm SD & $\mathrm{CI}_{95 \%}$ & Mean \pm SD & $\mathrm{CI}_{95 \%}$ & \\
\hline Age (280) & $52.57 \pm 16.77$ & [50.32 - 54.83] & $55.55 \pm 13.20$ & [52.29 - 58.82] & $53.26 \pm 16.04$ & [51.38 - 55.15] & 0.190 \\
\hline BMI (256) & $25.00 \pm 6.10$ & [24.14 - 25.87] & $28.57 \pm 7.33$ & [26.74 - 30.40] & $25.89 \pm 6.60$ & {$[25.08-26.71]$} & 0.003 \\
\hline WC (213) & $88.00 \pm 14.52$ & [85.92 - 90.09] & $94.54 \pm 14.42$ & [90.91 - 98.17] & $89.65 \pm 14.74$ & [87.81 - 91.48] & 0.002 \\
\hline WHr (211) & $0.92 \pm 0.07$ & {$[0.91-0.93]$} & $0.9337 \pm 0.06$ & {$[0.92-0.95]$} & $0.92 \pm 0.07$ & {$[0.91-0.93]$} & 0.178 \\
\hline HR (245) & $90.47 \pm 17.78$ & {$[87.92-93.02]$} & $84.47 \pm 13.26$ & [80.91 - 88.01] & $89.10 \pm 17.02$ & {$[86.96-91.24]$} & 0.020 \\
\hline $\mathrm{SBP}^{\star}(280)$ & $159.56 \pm 24.99$ & [156.21 - 162.93] & $162.71 \pm 22.56$ & [157.12 - 168.29] & $160.30 \pm 24.44$ & [157.42 - 163.17] & 0.365 \\
\hline $\mathrm{DBP}^{\star \star}(280)$ & $99.29 \pm 13.88$ & [97.43 - 101.16] & $96.52 \pm 15.94$ & [92.57 - 100.47] & $98.65 \pm 14.40$ & [96.95 - 100.34] & 0.175 \\
\hline $\mathrm{MAP}^{+}(280)$ & $119.33 \pm 15.58$ & [117.23 - 121.42] & $118.59 \pm 16.42$ & [114.52 - 122.66] & $119.16 \pm 15.75$ & {$[117.30-121.01]$} & 0.743 \\
\hline $\mathrm{PP}^{++}(280)$ & $60.27 \pm 19.02$ & {$[57.72-62.83]$} & $66.18 \pm 17.66$ & {$[61.81-70.56]$} & $61.65 \pm 18.85$ & [59.43 - 63.86] & 0.026 \\
\hline
\end{tabular}

$\mathrm{SBP}^{*}$ : systolic blood pressure; $\mathrm{DBP}^{* *}$ : diastolic blood pressure; $\mathrm{MAP}^{+}$: mean arterial blood pressure; $\mathrm{PP}^{++}$: pulsded pressure. 
Table 2. Sociodemographic data for 280 newly diagnosed or not treated hypertensive patients in the cardiology department of the University Hospital Gabriel Touré.

\begin{tabular}{|c|c|c|c|c|c|}
\hline Variables & & Ins- & Ins+ & Total & $\mathrm{p}$ \\
\hline \multirow[t]{2}{*}{ Sex } & $\mathrm{F}$ & 59.5 & 61.5 & 168 & 0.773 \\
\hline & M & 40.5 & 38.5 & 112 & \\
\hline \multirow[t]{5}{*}{ Age group (years) } & $<30$ & 11.6 & 3.1 & 27 & 0.057 \\
\hline & $30-44$ & 18.1 & 20 & 52 & \\
\hline & $45-59$ & 29.8 & 27.7 & 82 & \\
\hline & $60-74$ & 31.6 & 46.2 & 98 & \\
\hline & $\geq 75$ & 8.8 & 3.1 & 21 & \\
\hline \multirow[t]{2}{*}{ Activity status } & Active & 98.1 & 86.2 & 267 & $<0.0001$ \\
\hline & Retired & 1.9 & 13.8 & 13 & \\
\hline \multirow[t]{5}{*}{ Attended school level } & None & 67 & 43.1 & 172 & $<0.0001$ \\
\hline & $\begin{array}{l}\text { Less than } \\
\text { primary }\end{array}$ & 10.2 & 4.6 & 25 & \\
\hline & Primary & 14.9 & 10.8 & 39 & \\
\hline & Secondary & 4.2 & 20 & 22 & \\
\hline & University & 3.7 & 21.5 & 22 & \\
\hline
\end{tabular}

Table 3. Other CVrf in the sample of 280 newly diagnosed or not treated hypertensive patients in the cardiology department of the University Hospital Gabriel Touré.

\begin{tabular}{ccccc}
\hline Variables & Ins- & Ins+ & Total & $\mathrm{p}$ \\
\hline Tobacco smoking & $8.4 \%$ & $10.8 \%$ & 25 & 0.553 \\
Diabetes & 10.7 & 13.8 & 32 & 0.484 \\
Dyslipidémia & 0.5 & 1.5 & 2 & 0.368 \\
Alcohol consumption & 0.5 & 3.1 & 3 & 0.073 \\
Sedentary behavior & 23.3 & 20.0 & 63 & 0.582 \\
HIV infection & 0.5 & 0 & 1 & 0.582 \\
\hline
\end{tabular}

The same observation was made regarding the mean for cardiovascular medication with 27703 FCFA [21,910 - 33,497] for the Ins+ group against 16,010 $[13,289-18,732]$ for the Ins- group $(p<0.0001)$.

For the ECG, however, the opposite was observed with 6460 [5944 - 6976] for the patients ins- group against 5115 [4871 - 5360] for the Ins+ group, $p=0.001$ (Table 4). All other costs related to care were not significantly different between the 2 groups.

Highest costs were due to cardiovascular medication and blood tests with means of respectively 19,255 and 18,813 FCFA (Table 4). The drug prescriptions were dominated by the triad Calcium channel Inhibitor alone (CCI), 
Table 4. Management Cost for Ins- group compared to Ins+ group.

\begin{tabular}{cccccccc}
\hline \multirow{2}{*}{ Variables $(\mathrm{N})$} & \multicolumn{2}{c}{ Ins- } & \multicolumn{2}{c}{ Ins+ } & & Total & P \\
\cline { 2 - 7 } & Mean $\pm \mathrm{SD}$ & $\mathrm{CI}_{95 \%}$ & Mean $\pm \mathrm{SD}$ & $\mathrm{CI}_{95 \%}$ & Mean $\pm \mathrm{SD}$ & $\mathrm{CI}_{95 \%}$ & \\
\hline Consultation & $3124 \pm 25$ & {$[2774-3474]$} & $4064 \pm 34$ & {$[3210-4917]$} & $3351 \pm 28$ & {$[3014-3687]$} & 0.018 \\
Transport & $12,439 \pm 44$ & {$[6428-18,450]$} & $6887 \pm 16$ & {$[2763-11,010]$} & $11,182 \pm 39$ & {$[6443-15,920]$} & 0.335 \\
Chest x-ray & $11,409 \pm 13$ & {$[5523-17,295]$} & $21750 \pm 11$ & {$[4398-39,102]$} & $13,000 \pm 13$ & {$[7629-18,371]$} & 0.156 \\
ECG* & $6460 \pm 29$ & {$[5944-6976]$} & $5115 \pm 88$ & {$[4871-5360]$} & $6064 \pm 26$ & {$[5684-6446]$} & 0.001 \\
Blood tests & $17,775 \pm 14$ & {$[15,248-20,303]$} & $21514 \pm 12$ & {$[1,7912-25,117]$} & $18,813 \pm 14$ & {$[16,735-20,891]$} & 0.112 \\
Echocard. & $14,128 \pm 44$ & {$[13,198-15,058]$} & $13008 \pm 35$ & {$[11,913-14,103]$} & $13,777 \pm 42$ & {$[13,055-14,500]$} & 0.156 \\
Other & $28,041 \pm 19$ & {$[20,077-36,006]$} & $30748 \pm 26$ & {$[9055-52,441]$} & $28,718 \pm 20$ & {$[21,352-36,084]$} & 0.751 \\
Med 1 & $16,010 \pm 15$ & {$[13,289-18,732]$} & $27703 \pm 20$ & {$[21,910-33,497]$} & $19,255 \pm 17$ & {$[16,627-21,883]$} & $<0.0001$ \\
Med 2 & $8517 \pm 88$ & {$[4771-12,264]$} & $15388 \pm 85$ & {$[6479-24,296]$} & $9891 \pm 91$ & {$[6497-13,286]$} & 0.098 \\
Total & $50,072 \pm 58$ & {$[42,182-57,963]$} & $79670 \pm 52$ & {$[66,777-92,563]$} & $57,018 \pm 58$ & {$[50,139-63,897]$} & $<0.0001$ \\
\hline
\end{tabular}

ECG*: electrocar diogramm, Echocard.: echocardiography; Med $1^{* *}$ : cardiovascular medication; Med $2^{* * *}$ : non cardiovascular medication

Diuretic-Angiotensine converting enzym inhibitor (D-ACEI) and

Diuretic-CCl-ACEI (D-CCI-ACEI). These prescriptions made respectively 14.3, $10.4 \%$ and $8.9 \%$ of all prescriptions. There was no statistically significant difference between Ins+ and Ins- (Diagram 1).

Isolated Hypertension was by far the main diagnose with more than $60 \%$ (Diagram 2).

Completion rates of prescriptions (labor assessments and cardiovascular medication) were low around 50\% in the Ins- group (Diagram 3).

\section{Discussion}

Our study included newly diagnosed or untreated hypertensive patients who were seen consecutively during the study period. Our analysis considering the insurance status allowed us to have a sample of patients requiring additional tests before treatment start and the 2 groups presented no difference regarding age, blood pressure ( systolic and diastolic) (Table 1).

The study on this sample allowed us to make the following comments:

- We did not find similar data in the literature of the African subregion. Cost studies have, of course, been carried out but in hospital and retrospectively [7] either by estimation from the total costs of expenditure on health related institutions [9] or indirectly estimated from prescriptions [8]. Our study, however, systematically recorded costs at each consultation by directly asking the patient.

- The proportion of patients with medical insurance is still low, explainable by the fact that medical insurance started recently and mostly for salaried workers of the public and the private sector. This could also explain the fact that the proportion of the Ins+ group increased with the level of education and therefore the profession. 


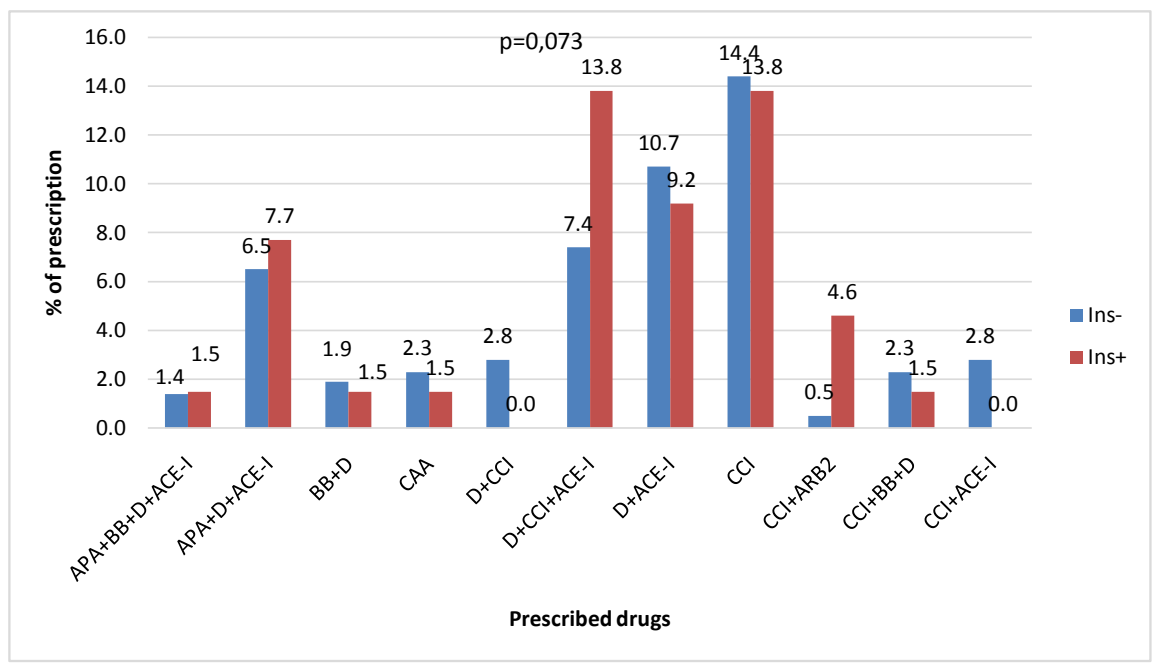

Diagram 1. Drug prescription for 280 newly or untreated hypertensive patients. APA: antiplatet agent, ARB2: angiotensine receptor blocker type 2, BB: $\beta$-blocker, CAA: central acting agent, D: diuretic, CCI: calcium channel inhibitor, ACEI: angiotensine converting enzym inhibitor.

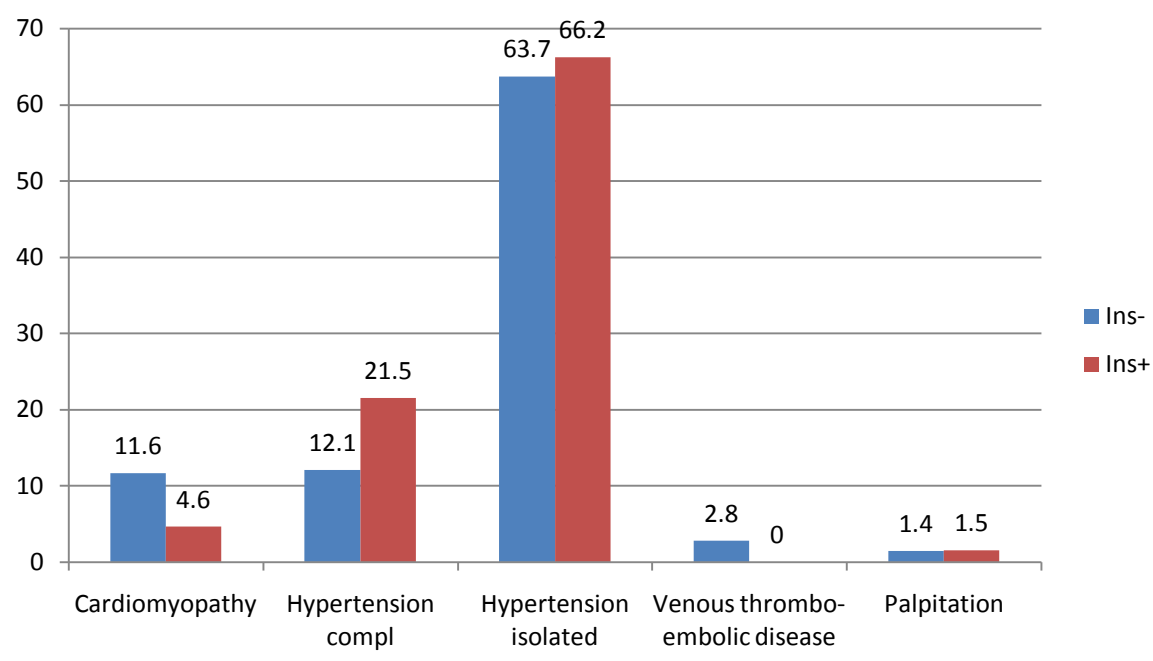

Diagram 2. Representation of $92.14 \%$ of the most frequent diagnoses based on the insurance status for 280 newly or untreated hypertensive patients.

- The total cost of care is higher for insured patients versus patients without insurance $(79,670 / 50,072)$, about 1.59 times. A possible explanation could be the fact that insured patients have to pay only a third of the amount necessary for all costs (medicaments, labor assessments), the remaining $2 / 3$ being covered by the health insurance. This could motivate the patients to consult more frequently and to pay fees for labor assessments and medicaments. But another possibility could be the fact that our insured patients are in a higher risk situation with a significantly higher BMI, waist circumference and PP (Table 1) and therefore require more explorations that leads to higher drug costs. The harmful role of these $3 \mathrm{CVrf}$ has been widely emphasized in the literature [11] [12] [13]. 


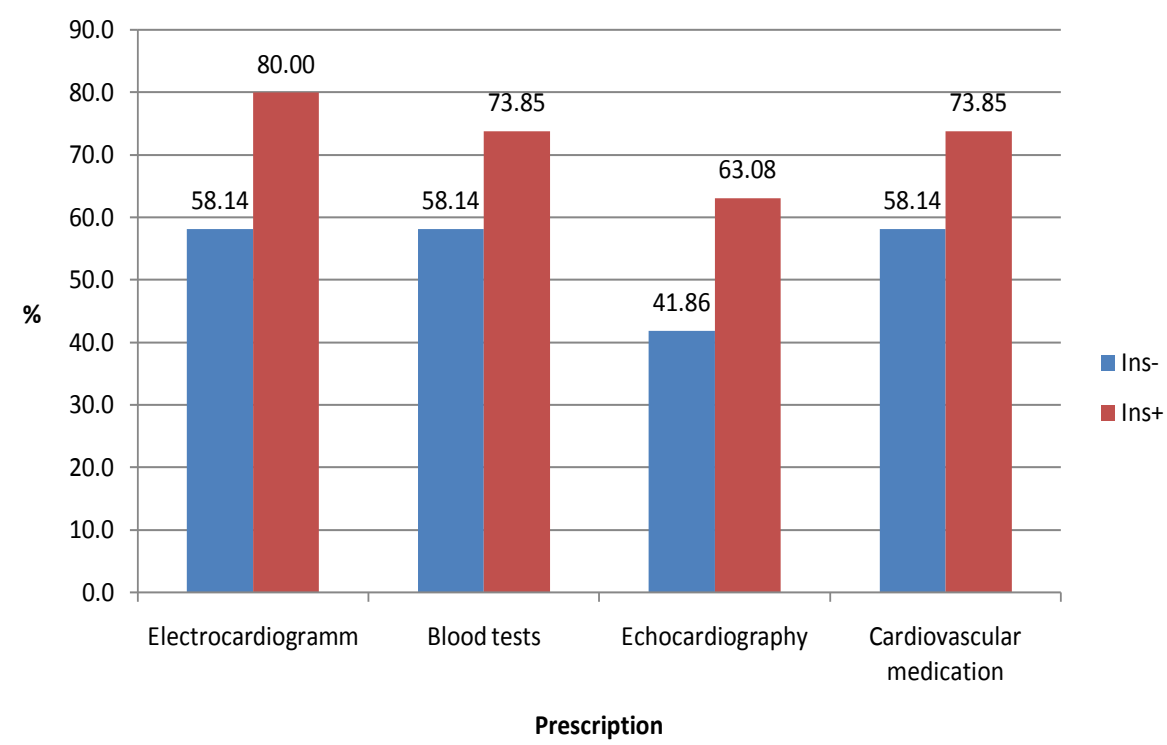

Diagram 3. Completion rates of physician prescriptions for 280 newly or untreated hypertensive patients

- Cardiovascular medications and blood tests were the main sources of expenditure for patients. When referring to the insurance status, only the cost of performing the ECG was higher for the Ins- group patients, all other costs being significantly higher for the Ins+ group. An explanation could be the low achievement rate of the ECG (58.1\%, Diagram 3) in the Ins- group. If all patients in the Ins- group (215) could perform ECG, the mean would also be around 5000, so practically identical to that for the Ins+ group.

- Regardless of the insurance status, the drug prescriptions were equivalent and dominated by 3 therapeutic classes: calcium channel inhibitors, angiotensin 2 converting enzyme inhibitors and diuretics.

- A comparison with a previous study of 1994 [10] is difficult for several reasons. Study design and collected items are different in both studies.

\section{Limitations}

The estimated costs for transportation are approximate because of the impossibility of quantifying certain trips, such as walking. The low rate of achievement of prescriptions in the Ins- group may be a factor in modifying the observed means.

\section{Conclusion}

Medical insurance has a few numbers of subscribers whereas the need for medical care is growing. Medical insurance increases the costs of care in a comprehensive way while facilitating access to care for those who are covered by a health insurance. In the absence of a general electronic medical record system, asking patients is the best alternative for estimating the management costs. 


\section{Conflicts of Interest}

The authors declare no conflicts of interest regarding the publication of this paper.

\section{References}

[1] Deaton, C., Froelicher, E.S., Wu, L.H., Ho, C., Shishani, K. and Jaarsma, T. (2011) The Global Burden of Cardiovascular Disease. European Journal of Cardiovascular Nursing, 10, S5-S13. https://doi.org/10.1016/S1474-5151(11)00111-3

[2] NCD Risk Factor Collaboration (NCD-RisC) (2017) Worldwide Trends in Blood Pressure from 1975 to 2015: A Pooled Analysis of 1479 Population-Based Measurement Studies with 19.1 Million Participants. The Lancet, 389, 37-55.

[3] Yusuf, S., Reddy, S., Ôunpuu, S. and Anand, S. (2001) Global Burden of Cardiovascular Diseases: Part II: Variations in Cardiovascular Disease by Specific Ethnic Groups and Geographic Regions and Prevention Strategies. Circulation, 104, 2855-2864.

[4] Hendriks, M.E., Wit, F.W.N.M., Roos, M.T.L., et al. (2012) Hypertension in Sub-Saharan Africa: Cross-Sectional Surveys in Four Rural and Urban Communities. PLoS ONE, 7, e32638. https://doi.org/10.1371/journal.pone.0032638

[5] Campbell, N.R. and Lemogoum, D. (2015) Hypertension in Sub-Saharan Africa: A Massive and Increasing Health Disaster Awaiting Solution. Cardiovascular Journal of Africa, 26, 152-154.

[6] Sarki, A.M., Nduka, C.U., Stranges, S., Kandala, N.-B. and Uthman, O.A. (2015) Prevalence of Hypertension in Low- and Middle-Income Countries: A Systematic Review and Meta-Analysis. Medicine, 94, e1959. https://doi.org/10.1097/MD.0000000000001959

[7] Mutowo, M.P., Lorgelly, P.K., Laxy, M., Renzaho, A.M.N., Mangwiro, J.C. and Owen, A.J. (2016) The Hospitalization Costs of Diabetes and Hypertension Complications in Zimbabwe: Estimations and Correlations. Journal of Diabetes Research, 2016, Article ID: 9754230. https://doi.org/10.1155/2016/9754230

[8] Ilesanmi, O.S., Ige, O.K. and Adebiyi, A.O. (2012) The Managed Hypertensive: The Costs of Blood Pressure Control in a Nigerian Town. The Pan African Medical Journal, 12, 96.

[9] Bovet, P., Shamlaye, C., Gabriel, A., Riesen, W. and Paccaud, F. (2006) Prevalence of Cardiovascular Risk Factors in a Middle-Income Country and Estimated Cost of a Treatment Strategy. BMC Public Health, 6, 9. https://doi.org/10.1186/1471-2458-6-9

[10] Diallo, B.A. (1994) Itineraires therapeutiques et coût thérapeutique de l'HTA en milieu urbain malien. Médecine d Afrique Noire, 41, 106-107.

[11] van Dijk, S.B., Takken, T., Prinsen, E.C. and Wittink, H. (2012) Different Anthropometric Adiposity Measures and Their Association with Cardiovascular Disease Risk Factors: A Meta-Analysis. Netherlands Heart Journal, 20, 208-218. https://doi.org/10.1007/s12471-011-0237-7

[12] Dobbelsteyn, C.J., Joffres, M.R., MacLean, D.R., Flowerdew, G., et al. (2001) A Comparative Evaluation of Waist Circumference, Waist-to-Hip Ratio and Body Mass Index as Indicators of Cardiovascular Risk Factors. The Canadian Heart Health Surveys. International Journal of Obesity, 25, 652-661. https://doi.org/10.1038/sj.ijo.0801582 
[13] Benetos, A., Safar, M., et al. (1997) Pulse Pressure: A Predictor of Long-Term Cardiovascular Mortality in a French Male Population. Hypertension, 30, 1410-1415. https://doi.org/10.1161/01.HYP.30.6.1410 